\title{
Prevalence of Cognitive Impairments in Patients with Good Functional Outcome in Late Phase Subarachnoid Hemorrhage
}

\section{Prevalência de alterações cognitivas em pacientes com bom desfecho funcional na fase tardia da hemorragia subaracnóidea}

\author{
Ariane Bernardes Camilo Castilho de Avellar ${ }^{1}$ Gerival Vieira Junior ${ }^{1}$ \\ Lucas Alverne Freitas de Albuquerque ${ }^{1}$ Rodrigo Alvares Paiva Macedo ${ }^{2}$ Marcos Dellaretti $1,2,3$ \\ ${ }^{1}$ Neurosurgery Department, Santa Casa de Belo Horizonte, Belo \\ Horizonte, MG, Brazil \\ 2 Faculdade de Ciências Médicas de Minas Gerais, Santa Casa de Belo \\ Horizonte, Belo Horizonte, MG, Brazil \\ Address for correspondence Ariane Avellar, MD, Instituto de Ensino e \\ Pesquisa da Santa Casa de Belo Horizonte, Rua Domingos Vieira, 590, \\ 3 Neurosurgery Department at the Hospital Mater Dei, Belo \\ Santa Efigênia, Belo Horizonte, MG, 30150-240, Brazil \\ Horizonte, MG, Brazil \\ Arq Bras Neurocir 2016;35:105-110.
}
Abstract
Keywords
- subarachnoid hemorrhage
- cognition
- embolization
- therapeutic
- microsurgery
- clinical evolution

\section{Resumo}
Palavras-chave
- hemorragia subaracnoide
- cognição
- embolização terapêutica
- microcirurgia
- evolução clínica

Prior studies have shown high prevalence of neuropsychological deficits after aneurysmal subarachnoid hemorrhage; however, few studies detect cognitive impairments in patients with good functional outcome, measured whith Rankin Modified Scale, in the late phase of subarachnoid hemorrhage. We confirmed a high prevalence of alterations in neuropsychological tests in 44 patients with Rankin Modified $\leq 2$. We proposed the application of simple and fast tests that allowed us to detect impairments with precision similar to that of complex cognitive batteries used in previous studies. We also attempt to confirm statistical association between factors that could be related to poor cognitive outcome, like Hunt-Hess scale classification, bleeding intensity measured with Fisher scale, therapeutic type (microsurgery ou embolization), and aneurysm localization; however, there was no significance.

Estudos anteriores mostraram que a prevalência de déficits neuropsicológicos após hemorragia subaracnóide aneurismática é alto, mas poucos estudos detectaram alterações cognitivas em pacientes com bom desfecho funcional, medido através da escada de Rankin Modificada, na fase tardia da hemorragia subaracnóide. O estudo confirmou em 44 pacientes com RankiN Modificado $\leq 2$ a alta prevalência de alterações em testes neuropsicológicos. Propusemos a aplicação de testes simples e rápidos, capazes de detectar alterações, com precisão semelhante a baterias cognitivas complexas utilizadas em estudos anteriores. Nós também avaliamos a associação estatística entre alguns fatores como a escala de Hunt-Hess $(\mathrm{HH})$, a intensidade do sangramento pela escala de Fisher, tipo de tratamento (microcirurgia ou embolização) e localização do aneurisma, ao pior desempenho cognitivo, no entanto não houve significância. received

October 25, 2015

accepted

December 21, 2015

published online

March 27, 2016
DOI http://dx.doi.org/

10.1055/s-0036-1579754. ISSN 0103-5355.
Copyright $(\underset{0}{ } 2016$ by Thieme Publicações License terms Ltda, Rio de Janeiro, Brazil
(요 (1) $\Theta$ 


\section{Introduction and Objective}

Spontaneous subarachnoid hemorrhage (sSAH) is a disease with high morbidity and mortality that affects the economically active population, since its peak incidence occurs between 40 and 60 years old. ${ }^{1,2}$

Deficits in memory, executive function, and language are common cognitive alterations following sSAH. ${ }^{1}$ Performances in these cognitive domains may improve with time, but some patients continue with deficits that may compromise their rehabilitation and occupational reintegration. ${ }^{3}$

The purpose of this study was to determine the prevalence of cognitive impairment in patients after $\mathrm{SSAH} 1^{3-8}$ considered to present good functional outcome according to the modified Rankin scale $($ score $\leq 2){ }^{9}$ In addition, we evaluate some factors as possible predictors of cognitive dysfunction. ${ }^{8,10,11}$

\section{Methods}

In this analytical cross-sectional study, we assessed patients with a previous diagnosis of aneurysmal SSAH treated at the Santa Casa de Belo Horizonte between June 2009 and June 2011. These patients were reassessed by December 2012, at least 12 months after the stroke, and were submitted to neurocognitive tests during outpatient consultations.

We recruited the patients by telephone and informed them of the purpose of the research. Several patients discontinued or refused to attend the outpatient service for any number of reasons, including death, lack of interest, distance from their residence, and difficulties related to transportation.

The study assessed 57 patients who suffered sSAH due to saccular aneurysm, who had been submitted to microsurgical or endovascular treatment. Of these, 13 patients were excluded because they presented a modified Rankin scale score $>2$ during outpatient evaluation.

The study was approved by the Research Ethics Committee of the Santa Casa de Belo Horizonte and Plataforma Brasil and all the participants signed a term of free, informed consent.

We obtained demographic data (age, sex, and education) together with medical and social history. Analysis of patient medical records provided data concerning their clinical status upon admission: Hunt-Hess scale $(\mathrm{HH})$ classification; bleeding intensity by the Fisher scale; treatment type, endovascular versus microsurgery; aneurysm location, anterior versus posterior circulation, and age. We then evaluated the associations between these factors during hospitalization and worse cognitive outcome.

We also applied the following instruments: the modified Rankin scale, Mini-Mental Status Examination (MMSE), the Memory Test Figures, Verbal Semantic Fluency Test (animal categories), and the Clock Drawing Test, based on the study of Nitrini et al. ${ }^{12}$ Among the instruments suitable for testing neuropsychological profiles on this group of patients, our choice took into account the ease of application and the time available during routine consultations.

Use of the MMSE aimed to assess global cognition and the results were determined using cutoff points suggested by a
Brazilian study, ${ }^{13}$ according to different educational levels: $<18$ points for illiterate individuals, $<23$ points for those with 1-3 years of education, $<25$ points for those with 4-7 years education, and $<26$ points for those with 8 or more years of education.

We assessed episodic memory using the Memory Test Figures. $^{12}$ This test consists of presenting 10 previously defined figures, revealed on a single card. Then, we conduct a naming exercise, recording both immediate and delayed incidental and spontaneous recall. Delayed recall occurs after interference mediated by performing the Verbal Semantic Fluency Test and the Clock Drawing Test. In the Verbal Semantic Fluency Test, the patient is expected to name examples of a specific semantic category for one minute. According to some authors, adequate accuracy in the test that was used in this study is nine animals for illiterate individuals, 12 animals for those with 1-7 years of education, and 13 animals for those with 8 or more years of education.

The Clock Drawing Test can provide important information concerning executive function, and was interpreted according to the score defined by Shulman in 1986. This scoring ranges from 0 to 5 , such that a perfectly designed clock scores 5 , with varying degrees of disruption up to the complete inability to draw a clock, which scores zero. A patient's test is considered to show anomalies when a score of 0,1 or 2 is recorded.

\section{Statistical Analysis}

We created the database and performed the statistical analyses using the software IBM SPSS 21.0 (Statistical Package for Social Sciences) for Mac.

The statistical treatment of the data included descriptive analysis of the results (means and frequencies), and analysis of the primary variables through statistical tests that investigated associations between the clinical outcome and prognostic factors. The nature of the variable (categorical, continuous) and their behavior indicated the use of specific tests. We used the Chi square test for categorical variables, to verify whether the frequency with which the event observed in the sample deviated from the expected frequency. When the expected frequency was lower than 5, we used Fisher's exact test. The confidence interval was $95 \%$ and the level of statistical significance adopted was $p \leq 0.05$. When age (continuous variable) was considered a potential predictive factor of anomalies in the tests, we calculated the mean and standard deviation of the values individually for each test. The Student $t$-test was used for comparison between groups.

We performed a multivariate analysis to evaluate the factors associated with anomalies in the MMSE, Memory Test Figures, Verbal Semantic Fluency Test, and Clock Drawing Test. We used a binary logistic regression model.

The variables analyzed were: the Hunt-Hess scale $(\mathrm{HH})$ classification, 1 and 2 or 3 and 4; Fisher scale grade (3 or different from 3); treatment (microsurgery or endovascular); aneurysm location (anterior or posterior circulation); and age (years).

Inclusion of the predictor variables in the multivariate analysis required a $p$ value less than 0.20 in the univariate 
analysis. We used the forward criteria, with inclusion of the variables in the model, one by one, from the most significant to least significant, according to the $p$ value determined in the univariate analysis. We adopted a 5\% level of significance to determine whether the variables would be maintained in the final model.

We evaluated the fit of the final model using the HosmerLemeshow goodness-of-fit test, after which we calculated the adjusted odds ratio (OR) estimates, together with their respective $95 \%$ confidence intervals $(95 \% \mathrm{CI})$.

\section{Results}

Fifty-seven patients ( 23 men and 34 women) were assessed, ranging in age from 20 to 75 years old (mean 48.8), with 2 to 16 years (mean 6.8) of education. We applied cognitive screening between 13 and 36 months (mean 25.4) after the stroke. Of these, 44 (77.2\%) had a modified Rankin scale score $\leq 2$, ranged in age from 20 to 67 years old (mean 48), had 4 to 16 years (mean 7.6) of education, and were included in the full assessment.

Regarding the $\mathrm{HH}$ scale upon hospital admission, $92.1 \%$ of patients (35/38) had a $\mathrm{HH}$ classification $\leq 2$ and $7.9 \%(3 / 38)$ were $\geq 3$. Regarding the Fisher scale, $45.5 \%$ (15/33) patients were graded as Fisher 1 or 2, and $54.5 \%$ (18/33) as Fisher 3 or 4. We did not include the $\mathrm{HH}$ scale classification for 6 patients and Fisher scale grade for 11 patients in the analysis due to lack of data in the patients' medical records.

Regarding the aneurysm location, $68.4 \%$ of patients (26/ 38 ) presented anterior circulation aneurysms, while $31.5 \%$ $(12 / 38)$ were located in the posterior circulation. The location of the aneurysm was not recorded for 6 patients.

Results on neurocognitive assessment of patients with a Rankin scale score $\leq 2$ was worse than expected for the MMSE in $18.2 \%$ (8/44) of patients, in the Memory Test Figures in $27.3 \%$ (12/44), in the Verbal Semantic Fluency Test in $47.7 \%$ (21/44), and in the Clock Drawing Test in 29.5\% (13/44) of patients (-Fig. 1). Furthermore, $65.9 \%$ of patients (29/44) showed anomalies in at least one test, $40.9 \%(17 / 44)$ in at least 2 tests, and 15.9\% (7/44) in at least 3 tests.

Taking into account factors evaluated as predictors of worse cognitive outcome following $\mathrm{SSAH}$, clinical status

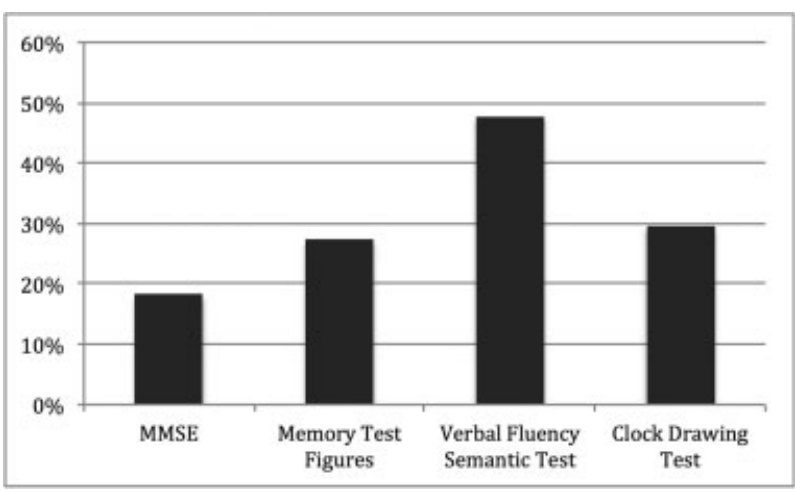

Fig. 1 Neurocognitive assessment of patients.
Table 1 Abnormal MMSE and predictors

\begin{tabular}{|c|c|c|}
\hline Factors & $\begin{array}{l}\text { Abnormal MMSE } \\
(\mathrm{n}, \%)\end{array}$ & $p$ value \\
\hline \multicolumn{3}{|l|}{$\mathrm{HH}$} \\
\hline $\mathrm{HH} \leq 2$ & $4 / 35(11.4 \%)$ & \multirow[t]{2}{*}{0.059} \\
\hline $\mathrm{HH} \geq 2$ & $2 / 3(66.6 \%)$ & \\
\hline \multicolumn{3}{|l|}{ Fisher } \\
\hline 1 or 2 & $3 / 15(20.0 \%)$ & \multirow[t]{2}{*}{0.63} \\
\hline 3 or 4 & $2 / 18(11.1 \%)$ & \\
\hline 3 & $3 / 11(27.3 \%)$ & 0.31 \\
\hline \multicolumn{3}{|l|}{ Location } \\
\hline Anterior Circulation & $5 / 26(19.2 \%)$ & \multirow[t]{2}{*}{0.64} \\
\hline Posterior Circulation & $1 / 11(9.1 \%)$ & \\
\hline \multicolumn{3}{|l|}{ Treatment } \\
\hline Microsurgery & $4 / 33(12.1 \%)$ & \multirow[t]{2}{*}{0.16} \\
\hline Endovascular & $2 / 3(66.6 \%)$ & \\
\hline \multicolumn{3}{|l|}{ Age } \\
\hline (mean 50.57; SD 4.87) & $37 / 44(84.1 \%)$ & 0.58 \\
\hline
\end{tabular}

upon admission, as determined by the HH scale, was the only factor significantly associated with anomalies in the MMSE. Among the patients admitted with a $\mathrm{HH}$ classification $\leq 2,11.4 \%$ presented values below normal, while for those with a $\mathrm{HH}$ of $\geq 3$, the rate was $66.3 \%$ ( $p=0.05$ ). None of the other factors evaluated (Fisher scale grade on admission, type of treatment, aneurysm location and age) showed any significant association (- Table $\mathbf{1}$ ).

Regarding the Memory Test Figures, Verbal Semantic Fluency Test, and the Clock Drawing Test, none of the associated factors showed a statistically significant association (-Tables 2, 3, and 4).

An anomaly in at least one of the tests was significantly associated with Fisher scale grade 3 upon admission (-Table 5).

For outcome anomalies in the Memory Test Figures, Verbal Fluency Semantic Test, and the Clock Drawing Test, none of the predictor variables remained in the final model, since all showed a $p$ value greater than 0.05 at multivariate analysis. For outcome anomalies in the MMSE, only the variable $\mathrm{HH}$ remained in the final model. This indicates that, regardless of other factors, the variable $\mathrm{HH}$ is associated with the MMSE test and patients with $\mathrm{HH}$ values greater than 2 have $\sim 15$ times more chance of presenting anomalies in the MMSE than those with a $\mathrm{HH}$ classification of 1 or $2(95 \%$ $\mathrm{CI}=1.13-212.18$ ).

\section{Discussion}

Analysis of the results obtained suggest that a cognitive assessment should be performed in patients following sSAH, even in cases where they are considered of good functional performance. Around $50 \%$ of previously employed 
Table 2 Abnormal Memory test figures and predictors

\begin{tabular}{|c|c|c|}
\hline Factors & $\begin{array}{l}\text { Abnormal Memory } \\
\text { Test Figures (n, \%) }\end{array}$ & $P$ value \\
\hline \multicolumn{3}{|l|}{$\mathrm{HH}$} \\
\hline $\mathrm{HH} \leq 2$ & $9 / 35(25.7 \%)$ & \multirow[t]{2}{*}{0.99} \\
\hline $\mathrm{HH} \geq 2$ & $1 / 3(33.3 \%)$ & \\
\hline \multicolumn{3}{|l|}{ Fisher } \\
\hline 1 or 2 & 4/15 (26.7\%) & \multirow[t]{2}{*}{0.99} \\
\hline 3 or 4 & $4 / 18(22.2 \%)$ & \\
\hline 3 & $1 / 11(9.1 \%)$ & 0.29 \\
\hline \multicolumn{3}{|l|}{ Location } \\
\hline Anterior Circulation & $6 / 26(26.1 \%)$ & \multirow[t]{2}{*}{0.69} \\
\hline Posterior Circulation & $4 / 12(33.3 \%)$ & \\
\hline \multicolumn{3}{|l|}{ Treatment } \\
\hline Microsurgery & $8 / 33(24.2 \%)$ & \multirow[t]{2}{*}{0.99} \\
\hline Endovascular & $1 / 5(20.0 \%)$ & \\
\hline \multicolumn{3}{|l|}{ Age } \\
\hline (mean 54.0; SD 3.30) & $32 / 44(72.7 \%)$ & 0.63 \\
\hline
\end{tabular}

patients do not return to the same occupational level after suffering a sSAH, which indicates the devastating nature of the sequelae. ${ }^{10}$ Impaired quality of life also occurs ${ }^{14}$ due to emotional disorders, cognitive impairment, or lack of clarification concerning the disease. ${ }^{15,16}$

Although the presence of cognitive impairment in patients who have suffered SSAH is known, ${ }^{1,4,7}$ this study

Table 3 Abnormal Verbal fluency semantic test and predictors

\begin{tabular}{|c|c|c|}
\hline Factor & $\begin{array}{l}\text { Abnormal Verbal } \\
\text { Semantic } \\
\text { Fluency Test (n, \%) }\end{array}$ & $p$ value \\
\hline \multicolumn{3}{|l|}{$\mathrm{HH}$} \\
\hline $\mathrm{HH} \leq 2$ & $16 / 35(45.7 \%)$ & \multirow[t]{2}{*}{0.23} \\
\hline $\mathrm{HH} \geq 2$ & $3 / 3(100 \%)$ & \\
\hline \multicolumn{3}{|l|}{ Fisher } \\
\hline 1 or 2 & $8 / 15(53.3 \%)$ & \multirow[t]{2}{*}{0.49} \\
\hline 3 or 4 & $7 / 18(38.9 \%)$ & \\
\hline 3 & $4 / 11(36.4 \%)$ & 0.47 \\
\hline \multicolumn{3}{|l|}{ Location } \\
\hline Anterior Circulation & $9 / 26(34.6 \%)$ & \multirow[t]{2}{*}{0.08} \\
\hline Posterior Circulation & $8 / 12(66.7 \%)$ & \\
\hline \multicolumn{3}{|l|}{ Treatment } \\
\hline Microsurgery & $14 / 33(42.4 \%)$ & \multirow[t]{2}{*}{0.64} \\
\hline Endovascular & $3 / 5(60 \%)$ & \\
\hline \multicolumn{3}{|l|}{ Age } \\
\hline (mean 51.24; SD 2.29) & $23 / 44$ (52.2\%) & 0.12 \\
\hline
\end{tabular}

Table 4 Abnormal Clock Drawing test and predictors

\begin{tabular}{|c|c|c|}
\hline Factors & $\begin{array}{l}\text { Abnormal Clock } \\
\text { Drawing Test (n, \%) }\end{array}$ & $p$ value \\
\hline \multicolumn{3}{|l|}{$\mathrm{HH}$} \\
\hline $\mathrm{HH} \leq 2$ & $8 / 35(22.9 \%)$ & \multirow[t]{2}{*}{0.16} \\
\hline $\mathrm{HH} \geq 2$ & $2 / 3(66.7 \%)$ & \\
\hline \multicolumn{3}{|l|}{ Fisher } \\
\hline 1 or 2 & $4 / 15(26.7 \%)$ & \multirow[t]{2}{*}{0.72} \\
\hline 3 or 4 & $6 / 18(33.3 \%)$ & \\
\hline 3 & $4 / 11(36.4 \%)$ & 0.70 \\
\hline \multicolumn{3}{|l|}{ Location } \\
\hline Anterior Circulation & $8 / 26(30.8 \%)$ & \multirow[t]{2}{*}{0.99} \\
\hline Posterior Circulation & $3 / 12(25.0 \%)$ & \\
\hline \multicolumn{3}{|l|}{ Treatment } \\
\hline Microsurgery & $9 / 33(27.3 \%)$ & \multirow[t]{2}{*}{0.30} \\
\hline Endovascular & $3 / 5(60.0 \%)$ & \\
\hline \multicolumn{3}{|l|}{ Age } \\
\hline (mean 43.69; SD 2.67) & $31 / 44$ (70.5\%) & 0.15 \\
\hline
\end{tabular}

highlighted the significant prevalence of alterations in the most commonly affected cognitive domains ${ }^{1,6}$ through the application of validated cognitive screening tests that are easy to apply. Previous studies, which have demonstrated impairment of cognitive performance in patients following sSAH, generally use extensive and complicated batteries of tests, require that the examiner be trained in complex rules

Table 5 Anomalies in at least one test and predictors

\begin{tabular}{|c|c|c|}
\hline Factors & $\geq 1$ abnormal test & $p$ value \\
\hline \multicolumn{3}{|l|}{$\mathrm{HH}$} \\
\hline $\mathrm{HH} \leq 2$ & $20 / 33(60.6 \%)$ & \multirow[t]{2}{*}{0.53} \\
\hline $\mathrm{HH} \geq 2$ & $3 / 3(100 \%)$ & \\
\hline \multicolumn{3}{|l|}{ Fisher } \\
\hline 1 or 2 & $10 / 15(66.6 \%)$ & \multirow[t]{2}{*}{0.29} \\
\hline 3 or 4 & $8 / 18(44.4 \%)$ & \\
\hline 3 & $4 / 11(36.4 \%)$ & 0.03 \\
\hline \multicolumn{3}{|l|}{ Location } \\
\hline Anterior Circulation & $12 / 25(48.0 \%)$ & \multirow[t]{2}{*}{0.07} \\
\hline Posterior Circulation & $10 / 12(83.3 \%)$ & \\
\hline \multicolumn{3}{|l|}{ Treatment } \\
\hline Microsurgery & $13 / 33(39.4 \%)$ & \multirow[t]{2}{*}{0.64} \\
\hline Endovascular & $3 / 4(75.0 \%)$ & \\
\hline \multicolumn{3}{|l|}{ Age } \\
\hline (mean 53.44; SD 3.38) & $37 / 44(84.1 \%)$ & 0.58 \\
\hline
\end{tabular}


of administration and scoring, and may need expensive testing materials. Moreover, the lack of uniformity between protocols makes comparisons between studies difficult.

In this study, anomalies in the Verbal Fluency Semantic test were the most frequent (47.7\%). This data are in agreement with a previous study that showed that, despite having a favorable neurological outcome according to the Glasgow Outcome Scale, $76 \%$ of a sSAH survivors were significantly impaired on the verbal and semantic fluency task. ${ }^{17}$ Pathological processes like degenerative and frontotemporal dementias, as well as frontal and temporal lobe lesions, produced anomalies in this test. ${ }^{18}$

Anomalies in the Clock Drawing Test suggest impairment of executive, visuospatial, and visuoconstrutive functions, as well as symbolic and graphomotor representation. These usually relate to frontal cortex and temporoparietal lesions, ${ }^{1,19,20}$ which were present in almost one third of patients. The Memory Test Figures and the MMSE completed the cognitive assessment battery and allowed us to assess various cognitive domains, including attention, language, and praxis.

The purpose of assessing patients with a Rankin scale $\leq 2$ was to confirm the presence of cognitive impairment following $\mathrm{SSAH}$ and to demonstrate that these alterations are present even in a subgroup that is classified as showing good functional performance. Although universally used in clinical practice and studies worldwide, the application of the modified Rankin scale only comprises motor skills, the degree of dependence, and interobserver variability, which has led to some discussion concerning its validity. ${ }^{4}$ This fact alerts us to the need to globally assess individuals who suffer from a sSAH, to determine the "real" functional outcome. A study that assessed patients with good results on the Glasgow Outcome Scale (GOS = 1) verified anomalies up to $53 \%$ of short-term and $21 \%$ of long-term memory tests when measured 6 months after the stroke. ${ }^{15}$ This frequency is high, like that in our study, in which the modified Rankin scale was used instead. We consider it advisable to perform any assessment at least 12 months after the stroke. This allows for greater reliability in the results, since neurological recovery undergoes a more active phase in the first few months following a stroke, until it stabilizes. ${ }^{21}$

Among the clinical variables studied, we only identified the association of two variables that could be considered significant predictors of cognitive impairment: a $\mathrm{HH}$ classification of $>2$ was associated with a greater number of abnormal results in the MMSE (i.e., greater severity on admission was associated with a lower than expected result in this test) and patients with Fisher scale grade 3, based on in their admission CT scan, presented anomalies in one or more cognitive tests, probably due to the higher frequency of cerebral vasospasm in these cases. ${ }^{10,22}$

According to some authors, there are numerous causes for adverse outcomes in SSAH patients that can act alone or in combination to adverse cognitive outcome. There are reports that sSAH microscopically alters brain function at the level of neuronal synapses, leading to neurological deficits. ${ }^{6}$ Increased intracranial pressure, which is common in patients with SSAH, can cause cholinergic dysfunction and diffuse brain damage, ${ }^{5}$ contributing to worse cognitive function. In addition, genetic factors, such as the expression of the ApoE phenotype, are associated with worse neurological outcome and impaired cognitive performance. ${ }^{23,24}$

Neuroimaging studies suggest that macroscopic alterations are responsible for cognitive deficits, such as the presence of delayed cerebral ischemia, which can increase the chances of severe neuropsychological deficits 5 -fold. ${ }^{16}$

Our study has certain limitations, including the small patient sample and the loss of important medical data, due, in part, to the retrospective nature of the assessment. These may have contributed to the fact that predictors of worse cognitive performance following sSAH, which are well established in the literature, did not achieve statistically significant values. ${ }^{1,5,7,8}$

Furthermore, not using a more extensive battery of neuropsychological tests that is targeted to specific cognitive domains prevented us from determining the prevalence of alterations in individual domains. However, we believe that the choice of shorter, simpler tests makes researching cognitive alterations more accessible to the neurologist or neurosurgeon in an outpatient care setting. We would like to emphasize that the purpose of this research did not include diagnosing dementia, rather being to warn clinicians of the possibility of worse cognitive performance in this population. In this study, grade 3 on the Fisher scale was significantly associated with anomalies in at least one test, and could be explained by the vasospasm. While anomalies in at least one test makes the screening process much more sensitive to cognitive alterations, it reduced the specificity of the assessment.

Our study demonstrates worse cognitive performance in patients that had suffered a spontaneous subarachnoid hemorrhage, even among those considered to show good functional outcome. It also highlights that cognitive tests that are easy to apply can identify these alterations. Thus, these findings contribute to extending current knowledge of the adverse consequences of spontaneous subarachnoid hemorrhage in patients' lives.

\section{References}

1 Al-Khindi T, Macdonald RL, Schweizer TA. Cognitive and functional outcome after aneurysmal subarachnoid hemorrhage. Stroke 2010;41(8):e519-e536

2 Berry E, Jones RA, West CG, Brown JD. Outcome of subarachnoid haemorrhage. An analysis of surgical variables, cognitive and emotional sequelae related to SPECT scanning. Br J Neurosurg 1997;11(5):378-387

3 Haley EC Jr. Measuring cognitive outcome after subarachnoid hemorrhage. Ann Neurol 2006;60(5):502-504

4 Quinn TJ, Dawson J, Walters MR, Lees KR. Functional outcome measures in contemporary stroke trials. Int J Stroke 2009;4(3): 200-205

5 Wong GKC, Wong R, Mok V, Wong A, Poon WS. Natural history and medical treatment of cognitive dysfunction after spontaneous subarachnoid haemorrhage: review of current literature with respect to aneurysm treatment. J Neurol Sci $2010 ; 299(1-2): 5-8$ 
6 Enciu A-M, Constantinescu SN, Popescu LM, Mureşanu DF, Popescu BO. Neurobiology of vascular dementia. J Aging Res 2011; 2011:401604

7 Haug T, Sorteberg A, Sorteberg W, Lindegaard K-F, Lundar T, Finset A. Cognitive outcome after aneurysmal subarachnoid hemorrhage: time course of recovery and relationship to clinical, radiological, and management parameters. Neurosurgery 2007; 60(4):649-656, discussion 656-657

8 Mayer SA, Kreiter KT, Copeland D, et al. Global and domainspecific cognitive impairment and outcome after subarachnoid hemorrhage. Neurology 2002;59(11):1750-1758

9 Quinn TJ, Dawson J, Walters MR, Lees KR. Reliability of the modified Rankin Scale: a systematic review. Stroke 2009;40(10):3393-3395

10 Ravnik J, Starovasnik B, Sesok S, et al. Long-term cognitive deficits in patients with good outcomes after aneurysmal subarachnoid hemorrhage from anterior communicating artery. Croat Med J 2006;47(2):253-263

11 Kreiter KT, Copeland D, Bernardini GL, et al. Predictors of cognitive dysfunction after subarachnoid hemorrhage. Stroke 2002;33(1): 200-208

12 Nitrini R, Lefèvre BH, Mathias SC, et al. Neuropsychological tests of simple application for diagnosing dementia. Arq Neuropsiquiatr 1994;52(4):457-465

13 Brucki SM, Nitrini R, Caramelli P, Bertolucci PH, Okamoto IH. Suggestions for utilization of the mini-mental state examination in Brazil. Arq Neuropsiquiatr 2003;61(3B):777-781

14 Greebe P, Rinkel GJE, Hop JW, Visser-Meily JMA, Algra A. Functional outcome and quality of life 5 and 12.5 years after aneurysmal subarachnoid haemorrhage. J Neurol 2010;257(12):2059-2064

15 Hütter BO, Gilsbach JM. Which neuropsychological deficits are hidden behind a good outcome (Glasgow = I) after aneurysmal subarachnoid hemorrhage? Neurosurgery 1993;33(6):999-1005, discussion 1005-1006

16 Stienen MN, Smoll NR, Weisshaupt R, et al. Delayed cerebral ischemia predicts neurocognitive impairment following aneurysmal subarachnoid hemorrhage. World Neurosurg 2014;82(5):e599-e605

17 Mavaddat N, Sahakian BJ, Hutchinson PJ, Kirkpatrick PJ. Cognition following subarachnoid hemorrhage from anterior communicating artery aneurysm: relation to timing of surgery. J Neurosurg 1999;91(3):402-407

18 Rodrigues AB, Yamashita ÉT, Chiappetta Ade ML. Teste de fluência verbal no adulto e no idoso: verificação da aprendizagem verbal. Rev CEFAC 2008;10(4):443-451

19 Hütter BO, Gilsbach JM, Kreitschmann I. Quality of life and cognitive deficits after subarachnoid haemorrhage. Br J Neurosurg 1995;9(4):465-475

20 Hadjivassiliou M, Tooth CL, Romanowski CA, et al. Aneurysmal SAH: cognitive outcome and structural damage after clipping or coiling. Neurology 2001;56(12):1672-1677

21 Ogden JA, Mee EW, Henning M. A prospective study of impairment of cognition and memory and recovery after subarachnoid hemorrhage. Neurosurgery 1993;33(4):572-586, discussion 586-587

22 Frontera JA, Fernandez A, Schmidt JM, et al. Defining vasospasm after subarachnoid hemorrhage: what is the most clinically relevant definition? Stroke 2009;40(6):1963-1968

23 Louko A-M, Vilkki J, Niskakangas T. ApoE genotype and cognition after subarachnoid haemorrhage: a longitudinal study. Acta Neurol Scand 2006;114(5):315-319

24 Alfieri A, Unterhuber V, Pircher M, et al. Psychosocial and neurocognitive performance after spontaneous nonaneurysmal subarachnoid hemorrhage related to the APOE-epsilon4 genotype: a prospective 5-year follow-up study. J Neurosurg 2008;109(6): 1019-1026 